\title{
First encounter of subclinical human Leishmania (Viannia) infection in the state of Rio Grande do Sul, Brazil
}

\author{
Aline Fagundes/+, Mauro CA Marzochi, Octavio Fernandes*, Mauricio A Perez**, \\ Armando O Schubach***, Tânia MP Schubach***, Maria RR Amendoeira****, \\ Eliame Mouta-Confort, Keyla BF Marzochi
}

National Reference Center for Diagnosis of Tegumentary Leishmaniasis, Laboratory of Parasitology, Department of Micro-ImmunoParasitology ***Department of Infectious Diseases, Instituto de Pesquisa Clínica Evandro Chagas-Fiocruz, Av. Brasil 4365, $21045-$ 900 Rio de Janeiro, RJ, Brasil *Laboratório de Epidemiologia Molecular de Doenças Infecciosas ****Laboratório de Toxoplasmose, Instituto Oswaldo Cruz-Fiocruz, Rio de Janeiro, RJ, Brasil **Departamento de Medicina Preventiva, Universidade Federal do Rio de Janeiro, Rio de Janeiro, RJ, Brasil

The objective of the present study was to evaluate the specificity of the Montenegro skin test (MST) in an area in Brazil, state of Grande do Sul State (RS), which was considered to be non-endemic for leishmaniasis. Sixty subjects presented a positive MST and were reevaluated by clinical examination, serology and polymerase chain reaction (PCR) of peripheral blood for the detection of subclinical Leishmania infection. None of the subjects presented clinical signs or symptoms of current leishmaniasis or a history of the disease. Leishmania (Viannia) DNA was detected in blood by PCR and hybridization in one subject. The PCR skin test-positive individual remained asymptomatic throughout the study. Clinical examination showed no scars suggestive of past cutaneous leishmaniasis. Human subclinical infection with Leishmania (Viannia) in RS was confirmed by $P C R$. This is the first report of subclinical infection with this parasite in the human population of this area.

Key words: Leishmania - PCR - Montenegro skin test - subclinical infection - Rio Grande do Sul - Brazil

Leishmania (Viannia) braziliensis infection occurs in most Brazilian states, and some authors believe that the dispersal of this parasite from the western Amazon is associated with anthroponotic action (Marzochi \& Marzochi 1994). The traditional clinical manifestations are single or multiple cutaneous lesions, but $L$. $(V$.) braziliensis has also been associated with mucosal or mucocutaneous leishmaniasis (Marzochi \& Marzochi 1994). Nevertheless, most infected individuals remain asymptomatic indefinitely, and show a cell-mediated or humoral immune response to Leishmania antigens or parasites in peripheral blood detected by polymerase chain reaction (PCR) (Follador et al. 2002, de Oliveira Camera et al. 2006).

The Montenegro skin test (MST) is the most widely used complementary test for the presumptive diagnosis of Leishmania infection. Classically, a positive MST is an indicator of previous contact with the parasite through natural inoculation after the bite of the sandfly. Alternatively, MST positivity can be the result of immunity acquired by vaccination (Mayrink et al. 1979, Marzochi et al. 1998), or nonspecific reactions to the merthiolate or phenol used in the MST as a preservative (Marzochi et

Financial support: Fiocruz/Ipec, MS/SVS, CNPq/FAPERJ, PAPES-Fiocruz

Corresponding author: aline.fagundes@ipec.fiocruz.br

Received 26 June 2007

Accepted 6 November 2007 al. 1998, Fagundes et al. 2003, 2007). In some cases, the nonspecific reaction was found to be morphologically identical to a classical positive MST (Marzochi et al. 1998, Fagundes et al. 2007), and it was not possible to discriminate between a false-positive MST due to merthiolate hypersensitivity and a true positive MST result.

In view of these nonspecific reactions, we performed a study in an area non-endemic for leishmaniasis in order to compare the MST response using antigens preserved in merthiolate or phenol. The study protocol has been described in detail by Fagundes et al. (2007). The study population consisted of 151 healthy male military volunteers from the state of Rio Grande do Sul (RS), Southern Brazil, where no case of leishmaniasis has been described so far. Informed consent was obtained from all volunteers and the study was approved by the Institutional Ethics Committee (Fiocruz) and the Brazilian Defense Ministry.

The Biomanguinhos ${ }^{\circledR}$ MST antigen (40 mg/ml Leishmania amazonensis protein antigen, IFLA/BR/1967/ PH8 strain) (Fiocruz, Rio de Janeiro, Brazil) preserved in $1: 10,000$ thimerosal or $0.4 \%$ phenol was used. All MST-positive and thimerosal- or phenol-allergic volunteers were reevaluated by clinical examination, serology and PCR. Venous blood samples $(3 \mathrm{ml})$ were collected into Vacutainer ${ }^{\circledR}$ tubes containing EDTA for DNA extraction. One-hundred microliter of buffy coat was used for DNA extraction with DNAzol ${ }^{\circledR}$ reagent (Gibco BRL), followed by washing in $95 \%$ ethanol, according to manufacturer instructions. Extraction was performed in a DNA workstation (Airclean System ${ }^{\circledR}$, Raleigh, NC, USA), with no more than six samples being processed simultaneously to avoid cross-contamination. Addition- 
ally, another blood sample was collected and serum was separated for the detection of Leishmania antibodies by indirect immunofluorescence (IFI) and ELISA (Madeira et al. 2000) and Trypanosoma cruzi by enzyme immunoassay and IFI (Silva et al. 2002). For PCR amplification, $1 \mathrm{ml}$ of a 1:20 dilution of the DNA extracted from each sample was submitted to hot-start PCR with primers that amplify the conserved region of the minicircle molecules present in all Leishmania species (Degrave et al. 1994). The reaction mixture contained $100 \mathrm{ng}$ of each primer $\left(5^{\prime}-(\mathrm{G} / \mathrm{C})(\mathrm{G} / \mathrm{C})(\mathrm{C} / \mathrm{G}) \mathrm{CC}(\mathrm{A} / \mathrm{C})-\right.$ CTAT(A/T)TTACACCAACCCC and 5'-GGGGAGGGGCGTTCTGCGAA), $200 \mathrm{mM}$ of each dNTP (GE Healthcare Life Sciences, São Paulo), 2.5 units of Taq polymerase (Ampliaq Gold, Perkin-Elmer, Norwalk) in the buffer supplied by the manufacturer, and $1.5 \mathrm{mM} \mathrm{MgCl}_{2}$. Amplification was carried out in a Perkin-Elmer 900 thermocycler under the following conditions: $94^{\circ} \mathrm{C}$ for 10 min, 30 cycles of $94^{\circ} \mathrm{C} / 30 \mathrm{~s}, 50^{\circ} \mathrm{C} / 30 \mathrm{~s}$ and $72^{\circ} \mathrm{C} / 30 \mathrm{~s}$, and a final cycle at $72^{\circ} \mathrm{C} / 10 \mathrm{~min}$. A negative control tube containing no DNA was included in each amplification. A positive control, consisting of 100 pg DNA extracted from an axenic culture of Leishmania braziliensis, was also performed. The DNA from the agarose gels was transferred to nylon membranes by capillary blotting using $0.4 \mathrm{~N} \mathrm{NaOH}$ and hybridized against Leishmania (Viannia)-specific probes as described elsewhere (Schubach et al. 1998, Pirmez et al. 1999).

The population sample for clinical and laboratory reevaluation consisted of 60 originally MST-positive individuals, 14 subjects with nonspecific reactions to thimerosal or phenol, and 77 MST-negative individuals as controls. None of these 151 individuals presented anti-Leishmania antibodies. Anti-T. cruzi antibodies were detected by ELISA in three volunteers (one of this MST-positive), and by IFI in two (one of this MST-positive). None of the volunteers presented anti-T. cruzi antibodies simultaneously detected by the two techniques. Of the 151 PCRs for the detection of Leishmania DNA, one was positive and hybridization showed that the product corresponded to Leishmania (Viannia) DNA. Hybridization did not enhance the sensitivity of the ethidium bromide-stained products, demonstrating that the other 150 samples were really negative. The positive PCR corresponded to an 18 year-old healthy male volunteer who tested positive in the MST with merthiolate antigen (11 $\mathrm{mm}$ induration diameter), and negative in the preservative test. The subject was asymptomatic, born in RS (Santa Maria city) and had never lived in a different place. The man did not present any scar or history of allergy or blood transfusion and was seronegative for Chagas' disease.

The MST is the most widely used presumptive diagnostic method for cutaneous leishmaniasis. It is a simple and reliable test, but nonspecific results may occur due to the presence of allergenic reagents in the preparation that are not related to Leishmania antigens (Pineda et al. 2001, Fagundes et al. 2007). Moreover, the test is unable to distinguish between active, inactive or past infection and may become positive in individuals vaccinated against leishmaniasis (Mayrink et al. 1979), thus indicating an immune response to Leishmania antigens in the absence of infection.

In clinical practice, methods for the etiological diagnosis of leishmaniasis (imprint, histopathology, in vitro culture and PCR) are used to confirm leishmaniasis infection in an MST-positive individual. These methods are generally applied in the presence of clinical disease. In our setting, since we studied asymptomatic MST- positive individuals, the most appropriate technique was PCR of peripheral blood because of its high sensitivity and specificity (Pirmez et al. 1999, de Oliveira Camera et al. 2006) which revealed one positive case. In addition to MST-positive subjects, we performed PCR on 91 other individuals (allergic or MST-negative) who tested negative.

In visceral leishmaniasis, PCR has been used as a tool for the evaluation of subclinical infection (Costa et al. $2000,2002)$. Some studies have shown that the persistence of Leishmania DNA in blood or bone marrow of treated visceral leishmaniasis patients is associated with disease relapse or the appearance of post-kala azar dermal leishmaniasis (Osman et al. 1997). Furthermore, PCR permitted the detection of Leishmania (Viannia) DNA in scars of clinically cured cutaneous leishmaniasis patients, demonstrating the persistence of the parasite (Schubach et al, 1998). Likewise, the scar of one of these patients was also positive by culture (Schubach et al. 1998). Assuming that a positive PCR corresponds to the presence of viable parasites, it might be considered to be an indicator of active infection (Tarleton et al. 1999).

The hypothesis of occurrence of persistent subclinical infection detected by a positive MST has been suggested since 1940 in Brazil (Pessoa \& Pestana 1940), and was later supported by PCR (Schubach et al. 1998, Costa et al. 2002, de Oliveira Camera et al. 2006). Whereas the MST does not discriminate among the infectious Leishmania species, the PCR-hybridization approach permits the identification of the infectious agent. In our case, the amplified product corresponded to DNA of the Viannia subgenus.

In conclusion, the finding of this MST-positive individual who presented Leishmania (Viannia) DNA detected by PCR, confirms the first case of subclinical human Leishmania infection in RS, Brazil. In contrast, the prevalence of positive responses to the MST is very high, excluding thimerosal- or phenol-allergic individuals. Other studies are in progress to identify Leishmania DNA in other populations, including domestic animals. The finding of MST positivity and Leishmania infection in individuals without symptoms and in an area where no human cases have been detected so far suggests the circulation of Leishmania in the study area, and the establishment of subclinical infection as the base of the "iceberg", whose peak is represented by the clinical confirmed cases. Besides, PCR might be a useful tool for surveillance in order to identify areas that are at risk for acquisition of the disease, and the circulating parasites, starting out from MST positive results. In fact, after the preparation of this manuscript, some cases of cutaneous leishmaniasis were notified (Rio Grande do Sul 2006) in another site in RS far from the study area. 


\section{ACKNOWLEDGEMENTS}

To the medical staff of the military units participating in the study, the Secretary of Health of Rio Grande do Sul, and the National Health Foundation, Brazil.

\section{REFERENCES}

Costa CH, Gomes RB, Silva MR, Garcez LM, Ramos PK, Santos RS, Shaw JJ, David JR, Maguire JH 2000. Competence of the human host as a reservoir for Leishmania chagasi. $J$ Infect Dis 182: 997-1000.

Costa CH, Stewart JM, Gomes RB, Garcez LM, Ramos PK, Bozza M, Satoskar A, Dissanayake S, Santos RS, Silva MR, Shaw JJ, David JR, Maguire JH 2002. Asymptomatic human carriers of Leishmania chagasi. Am J Trop Med Hyg 66: 334-337.

Degrave W, Fernandes O, Campbell D, Bozza M, Lopes U 1994. Use of molecular probes and PCR for detection and typing of Leishmania - a mini-review. Mem Inst Oswaldo Cruz 89: 463-469.

de Oliveira Camera P, Junger J, do Espirito Santo Silva Pires F, Mattos M, Oliveira-Neto MP, Fernandes O, Pirmez C 2006. Haematogenous dissemination of Leishmania (Viannia) braziliensis in human American tegumentary leishmaniasis. Trans R Soc Trop Med Hyg 100 :1112-1117.

Fagundes A, Marzochi KB, Marzochi MC 2003. Immediate and generalized reaction to Montenegro skin test. Rev Soc Bras Med Trop 36: 413-414.

Fagundes A, Marzochi MC, Perez M, Schubach A, Ferreira A, Silva JP, Schubach T, Marzochi KB 2007. Skin reactivity to thimerosal and phenol-preserved Montenegro antigen in Brazil. Acta Trop 101: 25-30.

Follador I, Araujo C, Bacellar O, Araujo CB, Carvalho LP, Almeida RP, Carvalho EM 2002. Epidemiologic and immunologic findings for the subclinical form of Leishmania braziliensis infection. Clin Infect Dis 34: E54-58.

Madeira M, Serra CM, Uchoa CM, Duarte R, Cruz DA, Perdomo C 2000. Canine leishmaniasis: a serological survey of $310 \mathrm{dogs}$ in Itaipu, Rio de Janeiro, Brazil. Cad Saude Públ 16: 568.

Marzochi KB, Marzochi MA, Silva AF, Grativol N, Duarte R, Confort EM, Modabber F 1998. Phase 1 study of an inactivated vaccine against American tegumentary leishmaniasis in normal volunteers in Brazil. Mem Inst Oswaldo Cruz 93: 205-212.

Marzochi M, Marzochi K 1994. Tegumentary and visceral leishmaniasis in Brazil- emerging anthropozoonosis and possibiliites for their control. Cad. Saúde Públ 10 (Suppl. 2): 359-375.

Mayrink W, da Costa CA, Magalhaes PA, Melo MN, Dias M, Lima AO, Michalick MS, Williams P 1979. A field trial of a vaccine against American dermal leishmaniasis. Trans $R$ Soc Trop Med Hyg 73: 385-387.

Osman OF, Kager PA, Zijlstra EE, el-Hassan AM, Oskam L 1997. Use of PCR on lymph-node sample as test of cure of visceral leishmaniasis. Ann Trop Med Parasitol 91: 845-850.

Pessoa SB, Pestana BR 1940. A intradermo-reação de Montenegro nas campanhas sanitárias contra a leishmaniose. Arch Hyg Saúde Públ 5:125-137.

Pineda JA, Macias J, Morillas F, Fernandez-Ochoa J, Cara J, de la Rosa R, Martin-Sanchez J, Gonzalez M, Garcia-Briones E, Delgado J, Lissen E 2001. False-positive results of leishmanin skin test due to phenol-containing diluent. Trans R Soc Trop Med Hyg 95: 173-174.

Pirmez C, Da Silva Trajano V, Oliveira-Neto MP, Da-Cruz AM, Goncalves-da-Costa SC, Catanho M, Degrave W, Fernandes O 1999. Use of PCR in diagnosis of human american tegumentary leishmaniasis in Rio de Janeiro, Brazil. J Clin Microbiol 37: 1819-1823.

Rio Grande do Sul 2006. Leishmaniose Tegumentar Americana. In: Secretaria Estadual da Saúde, Centro Estadual de Vigilância em Saúde, A saúde da população do Estado do Rio Grande do Sul, Porto Alegre, p. 117.

Schubach A, Haddad F, Oliveira-Neto MP, Degrave W, Pirmez C, Grimaldi G, Jr., Fernandes O 1998. Detection of Leishmania DNA by polymerase chain reaction in scars of treated human patients. J Infect Dis 178: 911-914.

Silva ED, Pereira VR, Gomes JA, Lorena VM, Cancado JR, Ferreira AG, Krieger MA, Goldenberg S, Correa-Oliveira R, Gomes YM 2002. Use of the EIE-recombinant-Chagasbiomanguinhos kit to monitor cure of human Chagas' disease. J Clin Lab Anal 16: 132-136.

Tarleton RL, Zhang L 1999. Chagas disease etiology: autoimmunity or parasite persistence? Parasitol Today 15: 94-99. 
